\title{
Major vascular injuries complicating knee arthroscopy
}

\author{
Radu Mircea Neagoe, Serban Bancu, Mircea Muresan, Daniela Sala \\ Second Department of Surgery, University of Medicine and Pharmacy, Tg Mures, Romania
}

Videosurgery Miniinv 2015; 10 (2): 266-274

DOI: $10.5114 /$ wiitm.2015.52559

\begin{abstract}
Starting with a case report, we made a detailed review of the literature, with the purpose of identifying and analyzing the type of iatrogenic vascular lesion following knee arthroscopy and the method of vascular repair. A PubMed literature search was undertaken to locate all reported cases of major vascular iatrogenic injuries during arthroscopic knee procedures. We identified 39 papers which report a total of 62 cases of major iatrogenic popliteal lesions after knee arthroscopy, between 1985 and 2014. The type of arthroscopic intervention performed, the type of iatrogenic vascular lesion encountered, the time passed until its discovery and treatment, the method of vascular reconstruction, and the postoperative course are presented. Postarthroscopy vascular complications are infrequent but potentially disastrous for the condition of the affected inferior limb. An early diagnosis and reintervention are mandatory for a good postoperative outcome.
\end{abstract}

Key words: reconstruction, arthroscopy, vascular trauma.

\section{Introduction}

Since its introduction in medical practice, arthroscopy has become the default method in the diagnosis and treatment of numerous knee conditions, being accredited as safe and having few complications $[1,2]$. Vascular complications, in particular, are extremely scarce, and the literature reports only a few cases of iatrogenic vascular traumas after this type of surgery $[3,4]$. Starting with a case report, we made a detailed review of the literature, with the purpose of identifying and analyzing the type of iatrogenic vascular lesion following knee arthroscopy and the method of vascular repair. Due to matters regarding the complexity of the vascular reintervention, we define major traumas as lesions which strictly concern the popliteal vessels (artery and vein) and which require more complex vascular reconstructions as compared with the lesions of collateral branches.

To the authors' knowledge, this is the first paper presenting a detailed literature review which ana- lyzes the major iatrogenic traumas of the popliteal vessels after knee arthroscopy.

\section{Case report}

The patient was a 33-year-old woman who had been presenting pain, instability and limited mobility of the left knee for the past 14 years and increasingly in the past 6 months. An arthroscopic exploration was performed, revealing degenerative meniscal lesions and a partial tear of both medial and lateral menisci. A partial meniscectomy and a shaving of the remnant degenerated meniscus were performed. The surgeon noticed more abundant bleeding at the moment of the resection of the posterior horn of the lateral meniscus but did not give it much importance at the time of the operation. The patient was discharged the day after the procedure, being allowed full weight-bearing. Three days after the procedure, she was readmitted with pain at the level of the left popliteal region and calf, a moderately swollen left

\section{Address for correspondence}

Radu Mircea Neagoe MD, Assoc. Prof., Second Department of Surgery, University of Medicine and Pharmacy, 38 Gh Marinescu St, 540139 Tg Mures, Romania, phone: 0040745609827, e-mail: neagoerm@gmail.com 
calf, as well as a bruising mass at the popliteal level with a systolic murmur heard over it.

The vascular consultation required urgently emphasized the pulsatile mass in the left popliteal fossa, paresis at the thigh level and weak-palpable distal pulses but without clear signs of peripheral ischemia at the level of the left leg.

The Doppler ultrasonography revealed a pulsatile cystic mass adjacent to the popliteal artery (pseudoaneurysm), having a large communication neck of $6 \mathrm{~mm}$ between each other. At the level of the pseudoaneurysm neck, we noticed a colored and spectral Doppler signal, increased systolic velocities (> $200 \mathrm{~cm} / \mathrm{s}$ ), and a turbulent flux with color-aliasing phenomena (Photo 1).

The ultrasonographic diagnosis was confirmed through an angio-CT examination and, later on, angiography, which both confirmed the presence of a left popliteal artery pseudoaneurysm (Photos $2 \mathrm{~A}$ and $\mathrm{B}$ ).

The left popliteal pseudoaneurysm $(5 \times 7 \mathrm{~cm})$ encountered during the surgery was evacuated and the artery was covered with a saphenous venous patch. The immediate postoperative evolution was uneventful, with no signs of peripheral ischemia. The follow-up at 12 months after the surgery found the patient with no clinical complaints and no signs of residual peripheral ischemia. Written consent was obtained from the patient for the case publication.

\section{Methods}

A PubMed literature search was undertaken to locate all reported cases of major vascular iatrogenic in-

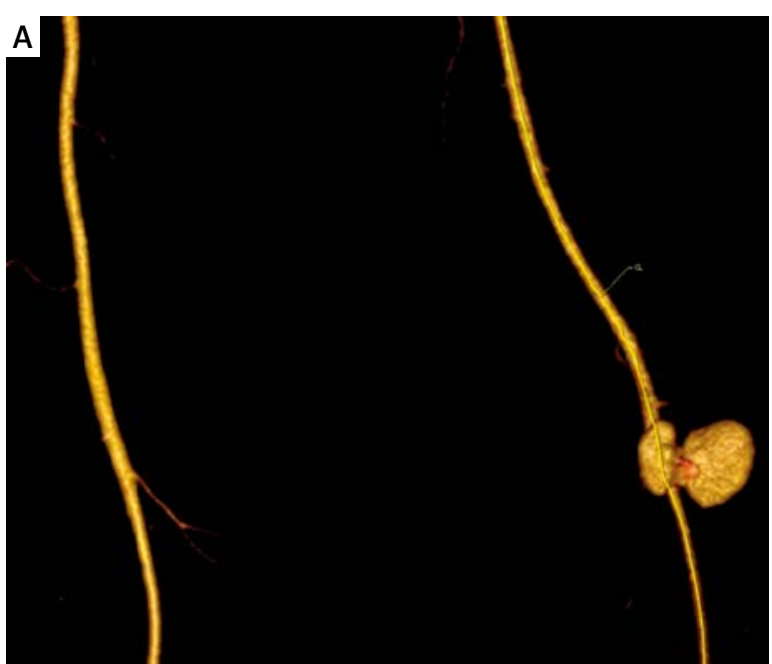

juries during arthroscopic knee procedures. Keyword search terms included iatrogenic vascular injuries AND arthroscopy, popliteal pseudoaneurysm AND arthroscopy, popliteal arterio-venous fistula AND arthroscopy, and other derivations of these terms.

Under the term of major iatrogenic vascular trauma after knee arthroscopy, we included those lesions which strictly concerned the popliteal artery and vein, clearly documented through imaging and confirmed in the surgery. On the other hand, we excluded cases in which the vascular lesion concerned the collaterals of the popliteal vessels or muscular branches on the basis of their reduced severity and complexity from the strict point of view of a vascular surgeon. Furthermore, we also excluded cases in

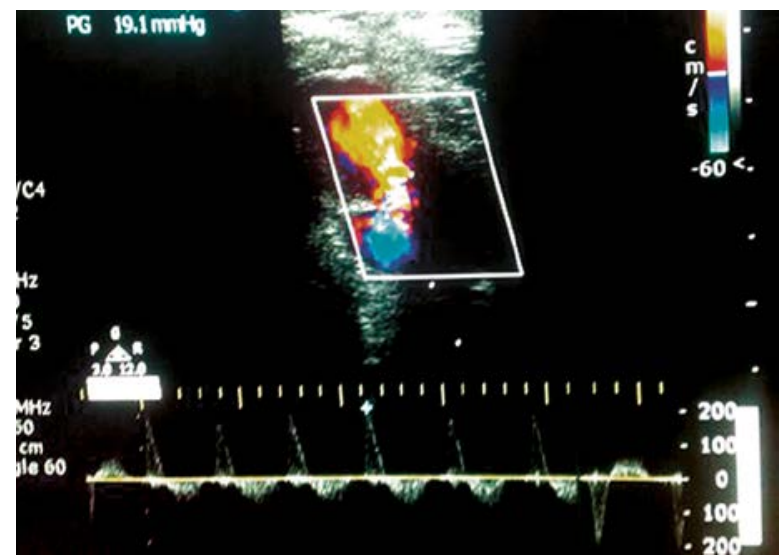

Photo 1. Doppler ultrasonography revealed a pulsatile cystic mass adjacent to the popliteal artery (pseudoaneurysm)

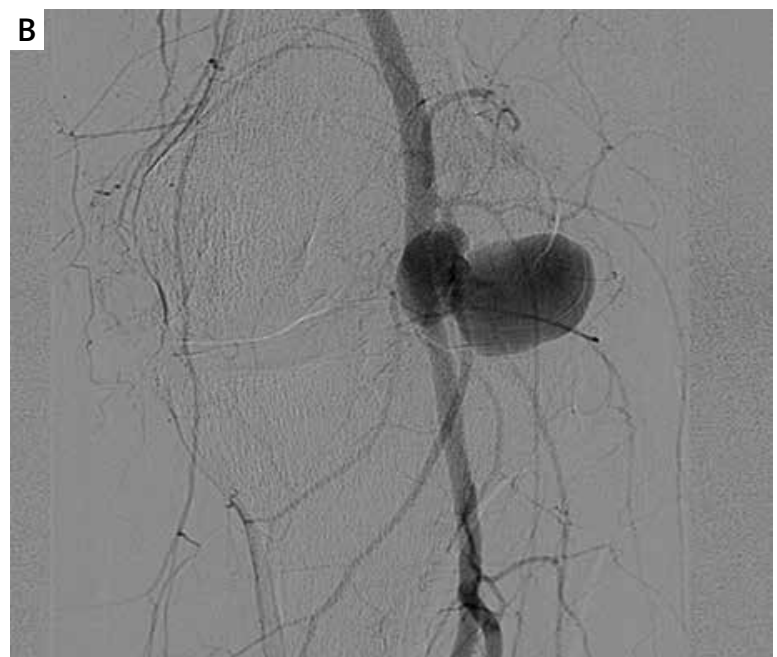

Photo 2. Angio-CT (A) and angiography (B): false aneurysm communicating with the popliteal artery - extravasation of contrast material to the popliteal area 
which the iatrogenicity might be debatable, such as acute postoperative popliteal artery occlusion due to/apparently determined by underlying atherosclerosis, thrombosis, the use of pneumatic tourniquet or arterial spasm.

When considered appropriate, a statistical analysis was applied by using the $\chi^{2}$ test ( $Z$ test); the results were interpreted relative to the significance threshold $p=0.05$, and statistical significance was considered for $p$-values below the significance threshold value.

\section{Results}

We identified 39 papers which report a total of 62 cases of major iatrogenic popliteal lesions after knee arthroscopy (including the case presented here) in a period of 30 years (1985-2014) [1, 2, 5-41]. Data regarding the type of arthroscopic intervention performed, the type of iatrogenic vascular lesion encountered, the time passed until its discovery and treatment, the method of vascular reconstruction, and the postoperative course are presented in Tables I and II. Dividing the entire studied period (1985-2014) into three decades, 1985-1995/19962005/2006-2014, we observed that the majority of cases (39 out of $62,62.90 \%$ ) appeared in the first period, 10 (16.12\%) cases in the second and 13 cases in the period 2006-2014 (20.96\%), the difference between the first analyzed period and the following two being statistically significant $(p=0.0001)$.

\section{Discussion}

Knee arthroscopy is a widespread technique considered to be safe and with a reduced overall rate of complications [1, 2]. Among these, vascular complications are exceptionally rare [2]. The studies concerning large series of knee arthroscopies do not describe this type of complication in particular [4], whereas the ones which do report such cases describe extremely reduced rates of complications, between $0.003 \%$ and $1 \%[1,2]$, and were written more than 30 years ago. However, the literature repeatedly reveals case reports and short series concerning this type of lesion. Therefore, we could consider the possibility that the previously mentioned numbers are underestimated, perhaps even due to the legal implications surrounding this diagnosis.

Our study concerns iatrogenic vascular lesions encountered after knee arthroscopy. From the analy- sis, we excluded case reports which described what we considered to be minor vascular popliteal lesions, such as genicular, tibial, and muscular vessels, which all are considerably easier to treat from the point of view of a vascular surgeon. Consequently, we only analyzed major iatrogenic popliteal traumas, whose repairs were dependent on the use of complex vascular procedures, i.e. saphenous vein graft, arterial reconstruction, or angioplasty patching.

As the majority of the authors have shown that demographic data (gender, age) and the cause of knee injury have no impact on complications $[5,6$, $13,18]$, we did not include these variables in our analysis. The major vascular lesions in our literature review were identified after diagnostic knee arthroscopies, cruciate ligament $(\mathrm{CL})$ reconstructions, popliteal cyst excisions, synovectomies or meniscectomies (Table II). Hence, Janseen et al. [28] reported one case of popliteal pseudoaneurysm after the anterior $C L$ repair, the lesions being produced by the drilling of the bicortical tibial screw for fixation of the graft. Another case of popliteal pseudoaneurysm reported by the same author was excluded, being apparently a pre-existing traumatic lesion [42]. Other authors have reported similar or different types of major popliteal vascular injuries after $C L$ reconstruction [7, 29, 31, 37, 40], including what seems to be the single case of an isolated popliteal vein lesion, unfortunately associated with mortality due to a cardiopulmonary arrest [36].

Popliteal pseudoaneurysms were also reported after cystectomies for popliteal cysts [32] or synovectomies $[9,30]$, but the majority of iatrogenic popliteal lesions appeared after arthroscopic meniscectomies. Several authors have tried to explain the mechanism and predispositional factors of the occurrence of the vascular injury during the arthroscopic meniscectomy through imaging, experimental or cadaveric studies [43]. The critical moment, frequently stressed by the authors in our literature search [9-11, 13-19], appears to be the resection of the meniscal posterior horn, as we also noted in our case. The factors which lead to this type of lesion are: close anatomical relation with the posterior capsule, forward kinking of the vessel during flexion, and limited visualization in the posterior compartment $[3,8,9,18]$. In the majority of cases, the lesion is not noticed during the arthroscopy, being either masked by the presence of the thigh tourniquet or confused with a minor lesion of the posterior capsule, as was noted in our case as well. 
Table I. Cases of major vascular trauma after knee arthroscopy procedures

\begin{tabular}{|c|c|c|c|c|c|c|}
\hline Author, year & Cases & $\begin{array}{l}\text { Arthroscopic } \\
\text { intervention }\end{array}$ & Vascular lesion & Onset & $\begin{array}{l}\text { Vascular } \\
\text { intervention }\end{array}$ & Observation \\
\hline De Lee, 1985 & 6 & $\mathrm{~N} / \mathrm{D}$ & Penetrating PA injuries & $\mathrm{N} / \mathrm{D}$ & $\mathrm{N} / \mathrm{D}$ & $\begin{array}{l}4 \text { patients with } \\
\text { amputation }\end{array}$ \\
\hline $\begin{array}{l}\text { Small, } \\
1985 / 1986\end{array}$ & 9 & N/D & Penetrating PA injuries & N/D & N/D & - \\
\hline $\begin{array}{l}\text { Beck et al., } \\
1986\end{array}$ & 1 & Arthroscopy & Pseudoaneurysm & 5 years & ISV bypass & Good outcome \\
\hline $\begin{array}{l}\text { Jeffries et al., } \\
1987\end{array}$ & 2 & Meniscectomy & Laceration (PA) & $5 \mathrm{~h}$ & Primary suture & - \\
\hline $\begin{array}{l}\text { Roth et al., } \\
1988\end{array}$ & 1 & $\begin{array}{l}\text { ACL recon- } \\
\text { struction }\end{array}$ & Extrinsic compression & 6 weeks & ISV bypass & - \\
\hline $\begin{array}{l}\text { Jimenez et al., } \\
1988\end{array}$ & 1 & Meniscectomy & $\begin{array}{l}\text { Pseudoaneurysm } \\
(P A+P V)+A V F\end{array}$ & 2 weeks & $\begin{array}{c}\mathrm{PA}+\mathrm{PV} \text { ePTFE } \\
\text { bypass }\end{array}$ & Good outcome \\
\hline $\begin{array}{l}\text { Tawes et al. } \\
1988\end{array}$ & 5 & Meniscectomy & $\begin{array}{c}\text { Pseudoaneurysm (3)/ } \\
\text { AVF (1)/N/D (1) }\end{array}$ & $\begin{array}{l}\text { Hours (2)/ } \\
2 \text { weeks (3) }\end{array}$ & Primary suture (2) & $\begin{array}{l}\text { Good outcome } \\
\text { (2) } 1 \text { massive } \\
\text { bleeding/1 am- } \\
\text { putation/1 CS }\end{array}$ \\
\hline $\begin{array}{l}\text { Vassallo et al., } \\
1989\end{array}$ & 1 & Meniscectomy & Pseudoaneurysm + AVF & 7 days & $\begin{array}{c}\text { PA + } P V \text { reconstruc- } \\
\text { tions }(\mathrm{TT})\end{array}$ & Good outcome \\
\hline $\begin{array}{l}\text { Lahl et al., } \\
1989\end{array}$ & 1 & Meniscectomy & AVF, CS & Hours & $\begin{array}{l}\text { PA reconstruction } \\
\text { (TT), PV suture, } \\
\text { fasciotomy }\end{array}$ & Good outcome \\
\hline $\begin{array}{l}\text { Mertl et al., } \\
1989\end{array}$ & 1 & Meniscectomy & Laceration (PA + PV) & $5 \mathrm{~h}$ & $\begin{array}{l}\text { ISV bypass/PV } \\
\text { ligation }\end{array}$ & $\begin{array}{l}\text { Persistent calf } \\
\text { edema }\end{array}$ \\
\hline $\begin{array}{l}\text { Brasseur et al., } \\
1990\end{array}$ & 1 & Meniscectomy & Pseudoaneurysm & 4 months & $\begin{array}{c}\text { ISV bypass/sympa- } \\
\text { thectomy }\end{array}$ & Good outcome \\
\hline $\begin{array}{l}\text { Munoz et al., } \\
1991\end{array}$ & 1 & Meniscectomy & Pseudoaneurysm & 15 days & ISV interposition & $\begin{array}{c}\text { Peripheral } \\
\text { hypoesthesia }\end{array}$ \\
\hline $\begin{array}{l}\text { Romdhane et al., } \\
1991\end{array}$ & 1 & Meniscectomy & Pseudoaneurysm & 1 month & $\begin{array}{c}\text { PA reconstruction } \\
(\mathrm{TT})\end{array}$ & Not mentioned \\
\hline $\begin{array}{l}\text { Ritt et al., } \\
1993\end{array}$ & 2 & Meniscectomy & Pseudoaneurysm $(1,2)$ & $\begin{array}{l}3 \text { weeks (1)/ } \\
\text { months (2) }\end{array}$ & $\begin{array}{l}\text { ISV interposition (1)/ } \\
\text { ISV bypass }(2)\end{array}$ & $\begin{array}{c}\text { Good outcome } \\
(1,2)\end{array}$ \\
\hline $\begin{array}{l}\text { Dinh et al., } \\
1993\end{array}$ & 3 & Meniscectomy & $\begin{array}{c}\text { Pseudoaneurysms (2)/ } \\
\text { pseudoaneurysm + } \\
\text { AVF (1) }\end{array}$ & $\begin{array}{l}1 \text { month }(1) / \\
5 \text { months }(2) / \\
3 \text { years }(3)\end{array}$ & $\begin{array}{l}\text { Primary suture }(1) / \\
\text { ISV bypass }(2,3)\end{array}$ & Good outcome \\
\hline $\begin{array}{l}\text { Potter et al., } \\
1995\end{array}$ & 2 & Meniscectomy & $\begin{array}{c}\text { Pseudoaneurysm (1)/ } \\
\text { acute postop } \\
\text { ischemia (2) }\end{array}$ & $\begin{array}{l}3 \text { days }(1) / \\
\text { hours }(2)\end{array}$ & ISV bypass $(1,2)$ & Good outcome \\
\hline $\begin{array}{l}\text { Furie et al., } \\
1995\end{array}$ & 1 & $\begin{array}{l}\text { Synovectomy } \\
\text { (redo) }\end{array}$ & Pseudoaneurysm + AVF & Hours & $\begin{array}{l}\text { ePTFE interposition/ } \\
\text { vein ligation }\end{array}$ & $\begin{array}{c}\text { Good outcome, } \\
\text { no sequelae }\end{array}$ \\
\hline $\begin{array}{l}\text { Guermazi et al., } \\
1996\end{array}$ & 1 & Meniscectomy & Pseudoaneurysm + DVT & 15 days & Primary suture & Good outcome \\
\hline $\begin{array}{l}\text { González-Fajar- } \\
\text { do et al., } 1997\end{array}$ & 1 & Meniscectomy & $N / D$ & $N / D$ & N/D & N/D \\
\hline $\begin{array}{l}\text { Hussein et al., } \\
1998\end{array}$ & 1 & Meniscectomy & Pseudoaneurysm & $\mathrm{N} / \mathrm{D}$ & ISV bypass & Good outcome \\
\hline
\end{tabular}


Table I. Cont.

\begin{tabular}{|c|c|c|c|c|c|c|}
\hline Author, year & Cases & $\begin{array}{l}\text { Arthroscopic } \\
\text { intervention }\end{array}$ & Vascular lesion & Onset & $\begin{array}{l}\text { Vascular } \\
\text { intervention }\end{array}$ & Observation \\
\hline $\begin{array}{l}\text { Kelm et al., } \\
1999\end{array}$ & 1 & Meniscectomy & AVF & 16 days & $\begin{array}{l}\text { Popliteal space } \\
\text { exploration/no vas- } \\
\text { cular procedure }\end{array}$ & Good outcome \\
\hline $\begin{array}{l}\text { Hofmann et al., } \\
2000\end{array}$ & 1 & Meniscectomy & Pseudoaneurysm & 7 days & Vein patch & Good outcome \\
\hline $\begin{array}{l}\text { Kiss et al., } \\
2001\end{array}$ & 1 & Meniscectomy & Pseudoaneurysm & 7 days & Vein patch & Good outcome \\
\hline $\begin{array}{l}\text { Regina et al., } \\
2002\end{array}$ & 1 & Meniscectomy & Pseudoaneurysm + DVT & 20 days & N/D & N/D \\
\hline $\begin{array}{l}\text { Tielliu et al., } \\
2002\end{array}$ & 1 & Meniscectomy & AVF/DVT & Weeks & $\begin{array}{l}3 \text { failed open vascu- } \\
\text { lar procedures/en- } \\
\text { dovascular (stent) }\end{array}$ & Satisfactory \\
\hline $\begin{array}{l}\text { Janseen et al., } \\
2004\end{array}$ & 1 & $\begin{array}{l}\text { ACL recon- } \\
\text { struction }\end{array}$ & Pseudoaneurysm & 12 days & $\begin{array}{l}\text { Vein patch, distal } \\
\text { thrombectomy }\end{array}$ & Good outcome \\
\hline $\begin{array}{l}\text { Makino et al., } \\
2005\end{array}$ & 1 & $\begin{array}{l}\text { PCL recon- } \\
\text { struction }\end{array}$ & Laceration (acute) & Immediate & ISV bypass & Good outcome \\
\hline $\begin{array}{l}\text { Lee et al., } \\
2007\end{array}$ & 1 & Synovectomy & Pseudoaneurysm & 11 days & ISV interposition & Good outcome \\
\hline $\begin{array}{l}\text { Kanko et al., } \\
2008\end{array}$ & 1 & $\begin{array}{l}\text { ACL recon- } \\
\text { struction }\end{array}$ & Giant pseudoaneurysm & N/D & N/D & N/D \\
\hline $\begin{array}{l}\text { Kp et al., } \\
2009\end{array}$ & 1 & $\begin{array}{c}\text { Cystectomy } \\
\text { (popliteal cyst) }\end{array}$ & Pseudoaneurysm & 2 months & Primary suture & Good outcome \\
\hline Nelms, 2009 & 1 & Meniscectomy & $\begin{array}{c}\text { Pseudoaneurysm + AVF } \\
+ \text { venous thromb }\end{array}$ & N/D & Primary suture & Good outcome \\
\hline $\begin{array}{l}\text { Rodrigues-Moro } \\
\text { et al., } 2012\end{array}$ & 1 & Meniscectomy & Complete laceration & 1 month & $\begin{array}{l}\text { ePTFE graft } \\
\text { interposition }\end{array}$ & Good outcome \\
\hline $\begin{array}{l}\text { Taboada et al., } \\
2012\end{array}$ & 1 & Meniscectomy & Pseudoaneurysm + AVF & N/D & Endovascular (stent) & \\
\hline $\begin{array}{l}\text { Nemani et al., } \\
2012\end{array}$ & 1 & $\begin{array}{l}\text { ACL recon- } \\
\text { struction }\end{array}$ & $\begin{array}{l}\text { Isolated injury popliteal } \\
\text { vein }\end{array}$ & Immediate & $\begin{array}{l}\text { No vascular } \\
\text { procedure }\end{array}$ & $\begin{array}{l}\text { Cardiopulmo- } \\
\text { nary arrest, } \\
\text { flash pulmo- } \\
\text { nary edema }\end{array}$ \\
\hline $\begin{array}{l}\text { Tam Kelvin } \\
\text { Kwok-Wai et al., } \\
2013\end{array}$ & 1 & $\begin{array}{c}\mathrm{ACL} \text { recon- } \\
\text { struction + } \\
\text { meniscectomy }\end{array}$ & Pseudoaneurysm/CS & 8 days & $\begin{array}{l}\text { ISV bypass/ } \\
\text { fasciotomy }\end{array}$ & Good outcome \\
\hline $\begin{array}{l}\text { Enriquez-Vega } \\
\text { et al., } 2013\end{array}$ & 2 & Arthroscopy & $\begin{array}{c}\text { Pseudoaneurysm } \\
\text { (thrombosed) and total } \\
\text { PV section (1) }\end{array}$ & $\begin{array}{l}72 \mathrm{~h}(1) / 3 \\
\text { weeks (2) }\end{array}$ & $\begin{array}{l}\text { 1) Amputation } \\
\text { 2) Primary suture }\end{array}$ & $\begin{array}{l}\text { Amputation (1)/ } \\
\text { good outcome } \\
\text { (2) }\end{array}$ \\
\hline $\begin{array}{l}\text { Aburahma, } \\
\text { Hass, } 2013\end{array}$ & 1 & Arthroscopy & Pseudoaneurysm & 4 days & Endovascular (stent) & Good outcome \\
\hline $\begin{array}{l}\text { Alserr et al., } \\
2014\end{array}$ & 1 & Meniscectomy & Pseudoaneurysm + AVF & 1 year & Endovascular (stent) & Good outcome \\
\hline $\begin{array}{l}\text { Lee et al., } \\
2014\end{array}$ & 1 & $\begin{array}{l}\text { ACL recon- } \\
\text { struction } \\
\text { (redo) }\end{array}$ & Pseudoaneurysm & 6 weeks & ISV interposition & $\begin{array}{c}\text { Good outcome/ } \\
\text { palsy } \\
\text { (peroneal) }\end{array}$ \\
\hline
\end{tabular}

N/D - Not determined, PA - popliteal artery, PV - popliteal vein, ACL - anterior cruciate ligament, $P C L$ - posterior cruciate ligament, CS - compartment syndrome, AVF - arterio-venous fistula, DVT - deep venous thrombosis, ISV - internal saphenous vein, ePTFE - expanded polytetrafluoroethylene, TT - termino-terminal anastomosis. 
The iatrogenic lesion was generally followed by the appearance of a pseudoaneurysm, defined through its saccular aspect on imaging, the lack of its own wall, and extensive hematoma, and clinically manifested as a popliteal pulsatile mass. In some cases, the arterial pseudoaneurysm was associated with a venous pseudoaneurysm [8] or an AV fistula [10, 17, 19, 33, 35, 39]. Kelm et al. [23] described a case of isolated AV fistula, discovered 14 days after arthroscopic meniscectomy. The literature review also emphasizes cases with a partial or complete popliteal artery and sometimes vein laceration [12, 29], which, surprisingly, were not all discovered immediately after the arthroscopic procedure [34].

In rare situations, the symptomatology was evident immediately after the surgery, allowing for a quick diagnosis, in the form of either severe limb ischemia $[9,11,18]$ or abundant bleeding through the level of an arthroscopic port [12]. However, almost $30 \%$ of patients with post-arthroscopic popliteal pseudoaneurysm could be asymptomatic [31]. In more than one third of the reviewed cases the onset was insidious, more than 15 days after the initial orthopedic surgical procedure, with symptoms including the presence of a painful pulsatile mass in the popliteal hollow, a swollen calf, or some degree of arterial deficiency. Sometimes the lesion was misinterpreted as a deep venous thrombosis (DVT) [20], much more frequently encountered after orthopedic surgery and which may also be associated with arterial trauma $[20,26]$. An important clinical detail in differentiating these two complications is represented by the association of pain symptoms, unspecific to DVT, as we noted in our case. In cases in which an arteriovenous fistula (AVF) is encountered the classical symptoms of arterial insufficiency are mixed with those of venous insufficiency manifested by edema, venous hypertension and varicosity; unrecognized AVF may also be followed by cardiac insufficiency [41].

The imaging was based firstly on performing a duplex Doppler, which could confirm the clinical diagnosis. However, the surgical treatment required more detailed anatomical information, provided by arteriography, CT angiography or magnetic resonance angiography. In the present case, we preferred to perform an urgent angio-CT scan, as well as angiography, in order to obtain a more detailed evaluation of the case.

A delayed diagnosis can have disastrous consequences for the viability of the affected inferior limb,
Table II. Summary of all reported cases

\begin{tabular}{|c|c|c|}
\hline Factor & Number & Percentage \\
\hline Total cases & 62 & \\
\hline Type of arthroscopic procedure: & 62 & \\
\hline Arthroscopy (diagnosis) & 4 & 6.45 \\
\hline Meniscectomy & 33 & 53.22 \\
\hline $\mathrm{CL}$ reconstruction & 6 & 9.67 \\
\hline Meniscectomy $+\mathrm{CL}$ reconstruction & 1 & 1.61 \\
\hline Cystectomy & 1 & 1.61 \\
\hline Synovectomy & 2 & 3.22 \\
\hline N/D & 15 & 24.19 \\
\hline Type of vascular lesion: & 63 & \\
\hline Pseudoaneurysm & 24 & 38.09 \\
\hline Pseudoaneurysm with AVF & 7 & 11.11 \\
\hline AVF & 4 & 6.34 \\
\hline Laceration & 4 & 6.34 \\
\hline Other and N/D & 24 & 38.09 \\
\hline Type of vascular intervention: & 58 & \\
\hline ISV bypass & 13 & 22.41 \\
\hline ISV interposition & 4 & 6.89 \\
\hline Primary suture & 8 & 13.79 \\
\hline Complex reconstructions & 3 & 5.17 \\
\hline Vein patch & 3 & 5.17 \\
\hline 3PTFE bypass/interposition & 3 & 5.17 \\
\hline $\begin{array}{l}\text { Other (including endovascular) } \\
\text { and N/D }\end{array}$ & 24 & 41.37 \\
\hline Time of diagnosis [days]: & 62 & \\
\hline$<15$ & 19 & 30.64 \\
\hline $15-30$ & 11 & 17.74 \\
\hline$>30$ & 12 & 19.35 \\
\hline N/D & 20 & 32.25 \\
\hline
\end{tabular}

N/D - Not determined, CL - cruciate ligament, AVF - arterio-venous fistula, ISV - internal saphenous vein, ePTFE - expanded polytetrafluoroethylene.

with percentages of below knee amputations reaching $50 \%$ in some cases $[1,2]$. Tawes et al. [9] described a series of 5 patients in whom 3 of the cases with late diagnosis and late vascular reintervention led to an unfavorable postoperative evolution, ending with an amputation in one case. In a series of 118,540 arthroscopic interventions, De Lee [1] reports six incisive lesions of the popliteal artery, with four patients ending with amputations. In our review we noted that the diagnosis was delayed (more than 30 days) in $19.35 \%$ of the situations. 
The type of vascular reinterventions performed in the 62 cases of major iatrogenic popliteal lesions were case specific, dependent on lesion type and location. The majority of authors preferred a vascular reconstruction through a bypass with reversed saphenous vein graft $[5,7,13,17,18,22,37]$. The synthetic graft (expanded polytetrafluoroethylene - ePTFE) was favored by few [8, 19, 34]; Jimenez et al. [8] described the sole case in which a double arterial and venous bypass with a PTFE graft was performed. Complex popliteal artery reconstructions by means of termino-terminal anastomoses are also reported in a few patients [10,11, 15]. Of the remaining cases, most underwent either a pinpoint suture of the injured vessel $[6,9,20,32,33]$ or the covering of the arterial defect with a venous patch [24, 26, 28], as done in our patient. In the last period therapeutic embolizations of popliteal aneurysms were also done successfully $[35,38,39]$. The association of an AVF fistula required its dismantling and a venous suture. Popliteal aneurysms are frequently complicated with thrombosis, the risk of distal embolization and subsequently limb loss being high; Tawes et al. [9] highlight the importance of routinely "pass[ing] distally a thrombectomy catheter to rule out and retrieve any clots that may have embolized".

The majority of the authors in our review emphasized the advantages of the posterior popliteal approach in dealing with this kind of lesion due to a better exposure of the popliteal neuro-vascular bundle $[9-11,13,24,29,33,34,37,40,41]$, the transversal incision being more favored than the S-shape incision.

Analyzing the literature, we noted that the compartment syndrome has, in some situations, been associated with major neurological [44] or vascular iatrogenic lesions, in particular in cases when signs of acute arterial insufficiency appeared immediately after the arthroscopy $[11,37]$. In these cases, the vascular intervention also included a fasciotomy, with the purpose of compartmental decompression and the reduction of ischemic and neurological functional sequelae.

We stressed the fact that the majority of major vascular complications after knee arthroscopies were encountered in the first decade (1985-1995) of the study, the difference with the two following periods (1996-2005, 2006-2014) being statistically significant. Indeed, in the first decade we found
39 reported cases of major vascular injuries, here including the largest series of cases described by De Lee [1], Small [2] and Tawes et al. [9]. Furthermore, the majority of amputations and sequelae following vascular lesions occurring in consequence of knee arthroscopy were encountered in the same period. Undoubtedly this observation shows the real problem of major vascular injuries caused during knee arthroscopy: from relatively often occurring at the beginning of the procedure, clearly illustrating at the time an expected learning curve, to very seldom nowadays.

In the authors' opinion, the main limitation of this study concerns the fact that in a number of cases, insufficient case data were found with regard to vascular lesions following knee arthroscopy, such that the percentage of undefined or unfound situations is significant. However, to the authors' knowledge, this study represents the first detailed review of the literature on this topic, drawing attention to the fact that postarthroscopy vascular complications are infrequent but potentially disastrous for the condition of the affected inferior limb. The consequences include irreversible ischemia, compartment syndrome, permanent neurological impairment, limb loss and even lethality. An early diagnosis and reintervention are mandatory for a good postoperative outcome. Orthopedic surgeons should keep in mind that this kind of complication could be encountered after knee arthroscopy and should be able to recognize its clinical picture.

\section{Conflict of interest}

The authors declare no conflict of interest.

\section{References}

1. De Lee J. Complications of arthroscopy and arthroscopic surgery: results of a national survey. Arthroscopy 1985; 1: 214-20.

2. Small NC, Committee on Complications of the Arthroscopy Association of North America. Complications in arthroscopy: the knee and other joints. Results of a national survey. Arthroscopy 1986; 2: 253-8.

3. Small NC. Complications in arthroscopic surgery of the knee and shoulder. Orthopedics 1993; 16: 985-8.

4. Shermann OH, Fox JM, Snyder SJ, et al. Arthroscopy - "no problem surgery”. J Bone Joint Surg Am 1986; 68: 256-65.

5. Beck DE, Robison JG, Hallett Jr JW. Popliteal artery pseudoaneurysm following arthroscopy. J Trauma 1986; 26: 87-9.

6. Jeffries JT, Gainor BJ, Allen WC, et al. Injury to the popliteal artery as a complication of arthroscopic surgery. A report of two cases. J Bone Joint Surg Am 1987; 69: 783-5. 
7. Roth JH, Bray RC. Popliteal artery injury during anterior cruciate ligament reconstruction: brief report. J Bone Joint Surg Br 1988; 70: 840 .

8. Jimenez F, Utrilla A, Cuesta C, et al. Popliteal artery and venous aneurysm as a complication of arthroscopic meniscectomy. J Trauma 1988; 28: 1404-5.

9. Tawes RL Jr, Etheredge SN, Webb RL, et al. Popliteal artery injury complicating arthroscopic menisectomy. Am J Surg 1988; 156: 136-8.

10. Vassallo P, Reiser MF, Strobel M, et al. Popliteal pseudoaneurysm and arteriovenous shunt following arthroscopic meniscectomy: case report. Cardiovasc Intervent Radiol 1989; 12: 142-4.

11. Lahl W, Katzer HJ, Trautvetter P, et al. latrogenic arteriovenous fistula of the popliteal artery following arthroscopic meniscectomy. Zentralbl Chir 1989; 114: 1420-3.

12. Merti P, Decoopman M, Woestelandt T, et al. Injury to popliteal artery and vein complicating an arthroscopy. Rev Chir Orthop Reparatrice Appar Mot 1989; 75: 408-11.

13. Brasseur P, Sukkarieh F. latrogenic pseudoaneurysm of the popliteal artery. Complication of arthroscopic meniscectomy. Apropos of a case. J Radiol 1990; 71: 301-4.

14. Muñoz A, Oller E. Aneurysm of the popliteal artery following arthroscopic meniscectomy. Angiologia 1991; 43: 115-7.

15. Romdhane BH, Neuenschwander S, Hautefort P, et al. Pseudoaneurysm of the popliteal artery following an arthroscopic meniscectomy: report of a pediatric case. Pediatr Radiol 1991; 21: 228.

16. Ritt MJ, Te Slaa RL, Koning J, et al. Popliteal pseudoaneurysm after arthroscopic meniscectomy. A report of two cases. Clin Orthop Relat Res 1993; 295: 198-200.

17. Dinh A, Brunet AP, Maatouk M, et al. Arterial complications of arthroscopic meniscectomies. Apropos of three cases. Ann Chir 1993; 47: 547-52.

18. Potter D, Morris-Jones W. Popliteal artery injury complicating arthroscopic meniscectomy. Arthroscopy 1995; 11: 723-6.

19. Furie E, Yerys P, Cutcliffe D, et al. Risk factors for arthroscopic popliteal artery laceration. Arthroscopy 1995; 11: 324-7.

20. Guermazi A, Zagdanski AM, de Kerviler E, et al. Popliteal artery pseudoaneurysm revealed by deep vein thrombosis after arthroscopic meniscectomy. Eur Radiol 1996; 6: 217-9.

21. González-Fajardo JA, Carpintero-Mediavilla LA. Lesión traumática de la arteria poplítea secundaria a meniscectomía. Clin Orthop Relat Res 1997; 2: 214-7.

22. Hussein MK, Lakkis SA. Pseudoaneurysm of the popliteal artery following arthroscopic meniscectomy. Bull Hosp Jt Dis 1998; 57: 162-4.

23. Kelm J, Ames M, Schmitt E. latrogenious arteriovenous fistula: rare complication after knee arthroscopy. Chirurg 1999; 70: 1174-6.

24. Hofmann W, Forstner R, Forstner K. Pseudoaneurysm of the pediatric popliteal artery after arthroscopic meniscus resection. Chirurg 2000; 71: 469-71.

25. Kiss H, Drekonja T, Grethen C, et al. Postoperative aneurysm of the popliteal artery after arthroscopic meniscectomy. Arthroscopy 2001; $17: 230-5$.
26. Regina G, Fullone M, Todisco C, et al. Association of deep venous thrombosis and popliteal pseudoaneurysm after arthroscopic meniscectomy. Minerva Chir 2002; 55: 803-5.

27. Tielliu IF, Verhoeven EL, Prins TR, et al. Stent-graft repair of a recurrent popliteal arteriovenous fistula. J Endovasc Ther 2002; 9: 375-8.

28. Janssen RP, Scheltinga MR, Sala HA. Pseudoaneurysm of the popliteal artery after anterior cruciate ligament reconstruction with bicortical tibial screw fixation. Arthroscopy 2004; 20: E4-6.

29. Makino A, Costa-Paz M, Aponte-Tinao L, et al. Popliteal artery laceration during arthroscopic posterior cruciate ligament reconstruction. Arthroscopy 2005; 21: 1396.

30. Lee B, Park SW, Nah JC, et al. Clinical image: popliteal artery pseudoaneurysm following arthroscopic synovectomy. Arthritis Rheum 2007; 56: 3432.

31. Kanko M, Buluc L. Very rare aetiology of giant popliteal pseudoaneurysm: anterior cruciate ligament surgery. Post Grad Med J 2008; 84: 158-9.

32. Kp V, Yoon JR, Nha KW, et al. Popliteal artery pseudoaneurysm after arthroscopic cystectomy of a popliteal cyst. Arthroscopy 2009; 25: 1054-7.

33. Nelms JK, Piper GL, Young JC. Arteriovenous fistula as a rare complication after arthroscopic meniscectomy. Am Surg 2009; 75: 432-4.

34. Rodríguez-Moro C, Sáinz-González F, Pérez-Piqueras A. Complete popliteal artery rupture one month after arthroscopic partial meniscectomy. Rev Esp Cir Ortop Traumatol 2012; 56: 153-5.

35. Taboada Martín R, Capel Alemán A. Arteriovenous fistula and popliteal pseudoaneurysm after arthroscopic meniscectomy: endovascular treatment with a Viabahn $\left.{ }^{\circledR}\right)$ stent. Radiologia 2012; 54: 94-5.

36. Nemani VM, Frank RM, Reinhardt KR, et al. Popliteal venotomy during posterior cruciate ligament reconstruction in the setting of a popliteal artery bypass graft. Arthroscopy 2012; 28: 294-9.

37. Kwok-Wai TK, Yiu-Chung W, Chi-Yuk L, Yuk-Yin C. Pseudoaneurysm of the popliteal artery after anterior cruciate ligament reconstruction surgery: a case report and literature review. J Orthop Trauma Rehabilitation 2014; 18: 44-6.

38. Aburahma Z, Hass MZ. Endovascular repair of a pseudoaneurysm of the popliteal artery following arthroscopic knee surgery: case report and review of literature. Vascular 2013; 21: 102-4.

39. Alserr AH, Antonopoulos CN, Papapetrou A, et al. Endovascular repair of popliteal artery pseudoaneurysm with arteriovenous fistula after knee arthroscopy: case report and literature review. Vasc Endovascular Surg 2014; 48: 166-70.

40. Lee GC, Kim DH, Park SH. Popliteal artery pseudoaneurysm after anterior cruciate ligament re-revision using a rigidfix cross pin. Knee Surg Relat Res 2014; 26: 121-4.

41. Enríquez-Vega ME, Cruz-Castillo JE, Pacheco-Pittaluga E, et al. Vascular injury as a complication of knee arthroscopic surgery. Report of two cases and review of the literature. Cir Cir 2013; 81: 454-8.

42. Janssen RPA, Sala HAGM, Prakken WJ. Simultaneous traumatic pseudoaneurysm and thrombosis of the popliteal artery after 
anterior cruciate ligament reconstruction. Inj Extra 2007; 38: 397-9.

43. Cosgarea AJ, Kramer DE, Bahk MS, et al. Proximity of the popliteal artery to the PCL during simulated knee arthroscopy: implications for establishing the posterior trans-septal portal. J Knee Surg 2006; 19: 181-5.

44. Noszczyk BH, Kresniak N, Nowak M. Superficial plane endoscopy for carpal tunnel release. Videosurgery Miniinv 2014; 9 : 262-6.

Received: 11.03.2015, accepted: 24.05.2015. 